\title{
Do Cory's shearwaters Calonectris diomedea synchronize laying among close neighborhoods? A reappraisal using data from artificial nest sites
}

Received: 13 April 2006 / Revised: 4 August 2006 / Accepted: 25 September 2006 / Published online: 17 October 2006

(C) Springer-Verlag and ISPA 2006

\begin{abstract}
Previous studies of Cory's shearwater nesting biology suggest that pairs nesting at very close range to one another lay their eggs more synchronously than the colony as a whole. However, such apparent synchrony could be confounded by the existence of spatial structure in the quality of nesting sites and, hence, quality of the birds occupying the nests. If laying dates differ between sites of different quality, then synchrony is just a by-product of the spatial arrangement of nest sites. In this study, we show that when studying laying dates in artificial nests of uniform quality, no local synchronization of laying could be detected. We point to other shortcomings of previous analyses and conclude that, although Cory's shearwaters show remarkably synchronized attendance behaviors at the nesting sites, there is no conclusive evidence showing that laying dates are influenced by the behavior of near neighbors.
\end{abstract}

Keywords Salvage Islands $\cdot$ Seabird $\cdot$ Timing of breeding

Communicated by P. MacGregor

P. Catry $(\bowtie)$

Unidade de Investigação em Eco-Etologia,

Instituto Superior de Psicologia Aplicada,

Rua Jardim do Tabaco 44,

1149-041 Lisboa, Portugal

e-mail: paulo.catry@netc.pt

\section{J. P. Granadeiro}

Centro de Biologia Ambiental, Departamento de Zoologia e

Antropologia, Museu Nacional de História Natural,

Universidade de Lisboa,

Rua da Escola Politécnica 58,

1269-102 Lisboa, Portugal

\section{P. Oliveira}

Serviço do Parque Natural da Madeira,

Secretaria Regional do Ambiente e dos Recursos Naturais,

Caminho do Meio, Quinta do Bom Sucesso,

9050 Funchal, Portugal

\section{Introduction}

Among colonially breeding seabirds, Cory's shearwaters Calonectris diomedea have been noticed for their remarkable degree of synchronization in certain activities at the nesting grounds (Hamer and Read 1987; Thibault et al. 1997). At the large colony of Selvagem Grande, northeast Atlantic, both breeders and nonbreeders are highly synchronized when coming to land, creating a very pronounced cyclic pattern in numbers attending the colony (Jouanin et al. 1989, personal observation). The periodicity of such cycles is variable (with a mean of approximately 9 days) and their driving forces unknown (Jouanin et al. 1989).

Synchronization has also been reported at smaller spatial scales within the nesting colony, with close neighbors allegedly being, on average, more synchronous in the timing of egg laying than the colony as a whole (Jones 1986a; Mougin et al. 2001). However, the evidence for such pattern seems relatively inconclusive for the following reasons. Jones (1986a) only visited the colony in August, during chick rearing, at a time when many nests would have already failed. Hence, his conclusions about the importance of the nearest neighbors in the synchronization of the nesting cycle are of limited value because nearest neighbors could not be reliably identified. Mougin et al. (2001) provided an extensive dataset on laying dates and distances between nests, but did not attempt to evaluate the influence of the nearest neighbor on laying dates. Both previous investigations, referred above, pooled data from nesting areas with nest sites varying dramatically in quality and density. If laying date is correlated with nest density and with nest-site location and quality (e.g., Jones 1986b), then any patterns of local synchronization could be spurious results arising from the spatial structure in the distribution of different types of nest sites.

In this paper, we reassess the hypothesis that Cory's shearwaters lay synchronously within close neighborhoods, using data from artificial nest sites of relatively uniform quality and density. This investigation is part of a broader effort to understand the factors responsible for the 
pronounced cyclic patterns of attendance at the Selvagem Grande colony.

\section{Materials and methods}

Fieldwork was carried out in May and June 2005 at Selvagem Grande $\left(30^{\circ} 09^{\prime} \mathrm{N}, 15^{\circ} 52^{\prime} \mathrm{W}\right)$. At this site, Cory's shearwaters lay in a wide diversity of locations, including disused rabbit burrows, deep and shallow caves, crevices on cliff-faces, under dense bushes on level ground, and in hollows on man-made structures. To avoid the confounding effects of such variety of nesting situations, we restricted our study to three subcolonies of birds nesting on manmade nest cavities, in walls located on the flat plateau of the island. Within each wall (which are approximately linear, 180,230 , and $280 \mathrm{~m}$ long), nests are all very similar in size and shape; hence, we assume that there is no spatial structure in nest site quality. There are very few shearwater nests on the flat ground surrounding each of these colonies. We studied a total of 231 occupied nests.

Laying dates were obtained by daily inspections of nest cavities throughout the laying period. Nests were numbered and distances between adjacent nests measured with a tape. From these data, distances between any two nests in each subcolony could be accurately calculated.

For an initial assessment of a possible relationship between internest distance and degree of synchronization, and the scale at which synchronization might occur, we produced graphs showing differences in laying dates between pairs of nests in relation to distance between those paired nests. These graphs, although useful for an initial assessment and visual inspection of the data, suffer from a large degree of pseudoreplication and so we followed with more rigorous tests for our general hypothesis.

For each wall, we performed a Mantel randomization test to evaluate if there was a significant correlation between the matrices of internest distances and the matrices of internest differences in laying dates. We performed 10,000 replications in each test.

To formally test the hypothesis that laying dates are influenced by the timing of breeding of the nearest neighbor, we took each nest at a time and calculated (1) the absolute difference in laying dates between the focal nest and its nearest neighbor and (2) the absolute difference between laying dates of the focal nest and another randomly chosen nest of the same wall (excluding nests at less than $4 \mathrm{~m}$ from the focal nest; the distance of $4 \mathrm{~m}$ was chosen on the basis of previous reports of synchronization at this level of spatial scale; Mougin et al. 2001). These two values formed a pair of observations that entered a paired $t$ test. No pair of nests contributed with more than one datum to these analyses.

\section{Results}

Mean laying dates were similar in all three subcolonies (Table 1. ANOVA: $F_{2,229}=1.1, p=0.35$ ). The inspection of Fig. 1 does not suggest any relationship between distance among nests and differences in laying dates. This is confirmed by the Mantel randomization tests that indicate a lack of relationship between differences in laying date and distance between nests: wall 1 , observed correlation= $-0.03, p=0.71$; wall 2 , correlation $=-0.05, p=0.67$; wall 3 , correlation $=-0.03, p=0.78$ ).

Furthermore, tests comparing differences in laying dates between nearest neighbors and randomly chosen distant neighbors revealed no differences that would indicate a degree of synchrony (Table 1). We repeated the analyses using different minimum distance cut-off points, for distant neighbors, but results were unchanged. Doing a joint analysis pooling all three walls (a more powerful test, but with the disadvantage of mixing walls with slightly different characteristics) still holds no significant difference between nearest neighbors and distant pairs (paired $t$ test, $t=0.38, d f=140, p=0.70$ ).

\section{Discussion}

We could find no evidence for a spatial synchronization of laying within subcolonies of Cory's shearwaters of relatively uniform characteristics in relation to nest site quality and nest spacing. Hence, it is possible that previous reports of synchronous laying were the result of spatial structure in nest density/quality and correlated timing of breeding. Our study was carried out in a year with good environmental conditions and at a site where birds generally breed very successfully; breeding success (chicks fledged per eggs laid) in the studied walls, in 2005, was $68.5 \%$ ( $n=267$ study nests). We should also point out that

Table 1 Differences in laying dates (in days) between nearest neighbors and randomly chosen distant neighbors, with information on distances between nests

\begin{tabular}{lllllll}
\hline $\begin{array}{l}\text { Wall Laying date (days } \\
\text { after 25 May) }\end{array}$ & $\begin{array}{l}\text { Diff. to nearest } \\
\text { neighbor (d) }\end{array}$ & $\begin{array}{l}\text { Diff. to distant } \\
\text { neighbor (d) }\end{array}$ & $\begin{array}{l}\text { Paired } t \text { test } \\
\text { Dist. to nearest } \\
\text { neighbor }(\mathrm{m})\end{array}$ & $\begin{array}{l}\text { Dist. to distant } \\
\text { neighbor (m) }\end{array}$ & $\begin{array}{l}\text { No. of nests separating } \\
\text { distant neighbor }\end{array}$ \\
\hline 1 & $5.2 \pm 3.64$ & $4.0 \pm 3.4$ & $3.9 \pm 3.0$ & $\begin{array}{l}0.16, n=54,1.4 \pm 1.1 \\
p=0.87\end{array}$ & $21.0 \pm 35.9$ & $28.9 \pm 16.9$ \\
2 & $5.9 \pm 4.01$ & $3.7 \pm 3.0$ & $3.3 \pm 2.5$ & $\begin{array}{l}0.49, n=28,2.9 \pm 3.8 \\
p=0.62\end{array}$ & $77.0 \pm 61.5$ & $17.0 \pm 8.3$ \\
3 & $5.9 \pm 3.27$ & $3.7 \pm 2.4$ & $3.6 \pm 3.6$ & $\begin{array}{l}0.09, n=59,1.9 \pm 1.2 \\
p=0.92\end{array}$ & $85.6 \pm 55.3$ & $32.4 \pm 20.1$ \\
\end{tabular}



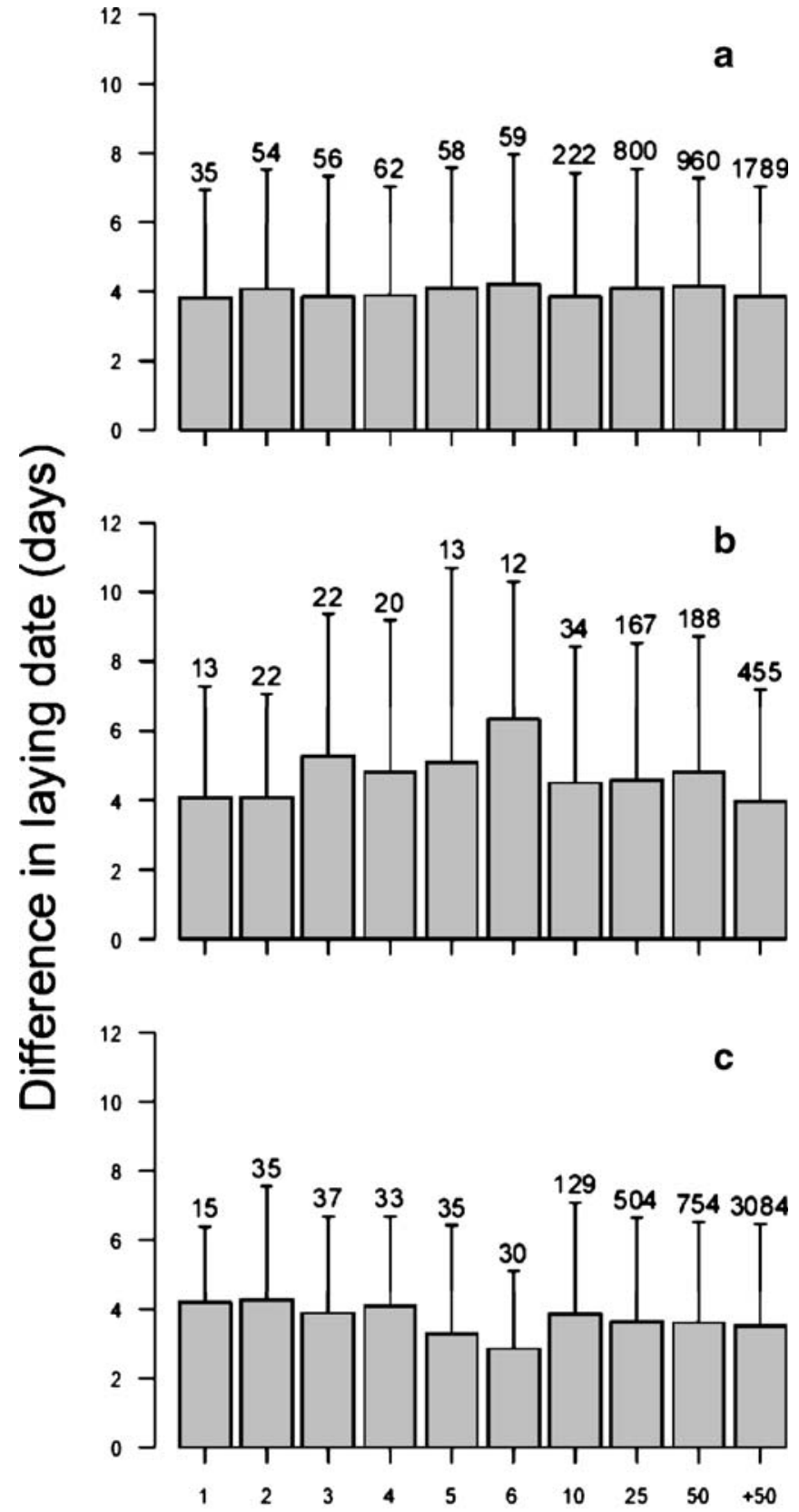

\section{Distance between nests $(\mathrm{m})$}

Fig. 1 Differences in laying dates (means \pm SD) between pairs of nests, within three walls $(\mathbf{a}, \mathbf{b}$, and $\mathbf{c})$, in relation to distance between those paired nests (sample size depicted above bars). Note that because each nest is compared to every other nest in the same wall, sample sizes (of pairs of nests) far exceed the number of nests studied

previous analyses were either based on indirect measurements of laying dates (Jones 1986a) or used statistical techniques that did not account for the dangers of wide scale pseudoreplication (Mougin et al. 2001). The results of this last study are particularly puzzling because even though some of its analyses do suggest some synchronization, other analyses and the visual inspection of the graphed data might be interpreted as evidence for no synchroniza- tion at all. In particular, when visually comparing their large data set (their Fig. 1) for nests at very close range (1$2 \mathrm{~m}$ ) with widely spaced nests (>10 m), there seem to be no differences in the degree of synchronization.

It could be argued that our study site is atypical. However, we should point out that nest density at our study sites is broadly similar to what is found throughout most of the colony. One difference between our study nests and some nests elsewhere in the island is that in other areas, sometimes (in a small minority of cases), shearwaters in adjacent nests can maintain direct visual contact between themselves. We do not know if such direct contact can affect synchronization. However, as explained above, data presented by Mougin et al. (2001) suggest that rather than the nearest neighbors being synchronized, it is the birds separated by intermediate distances that would be out of synchrony. Hence, we find it unlikely that it is the direct visual contact, possible in a minority of the nests of Selvagem Grande, that is responsible for the alleged synchronization reported in previous studies. However, a more detailed analysis of this particular issue is maybe warranted.

Synchronization among close neighborhoods can bring advantage to densely nesting seabirds, such as guillemots Uria aalge; thanks to improved defense against predators (e.g., Birkhead 1977; Hatchwell 1991). However, such an effect is unlikely to operate with birds, like shearwaters, that nest in relatively spaced cavities and without any communal nest defense or physical protection provided by neighbors.

Although our study suggests that Cory's shearwaters are not locally synchronous at laying, there can be little doubt that synchronization occurs in other aspects of their behavior, namely, in the timings of landfall of both breeders and nonbreeders (e.g., Hamer and Read 1987; Jouanin et al. 1989; Bretagnolle 1990; Thibault et al. 1997). More research is needed to clarify the proximate and ultimate driving forces that underlie such mysterious patterns of synchrony.

Acknowledgements Rui Rebelo, Maria Dias, David Santos, and particularly Sandro Correia provided an invaluable help during fieldwork. This study is an output from a project on the ecology of Cory's shearwaters (PDCT/MAR/58778/2004) supported by Fundação para a Ciência e a Tecnologia (FCT, Portugal). J.P. Granadeiro and P. Catry benefited from postdoctoral fellowships from FCT (BPD/11544/02 and BPD/11631/02) and further support was received through Programa Plurianual (UI and D 331/94).

\section{References}

Birkhead TR (1977) The effect of habitat and density on breeding success in the Common Guillemot (Uria aalge). J Anim Ecol 46:751-764

Bretagnolle V (1990) Effet de la lune sur l'activité des Pétrels (Aves) aux îles Salvages (Portugal). Can J Zool 68:1404-1409

Hamer K, Read H (1987) Patterns of return to land in a colony of Cory's Shearwater Calonectris diomedea on Selvagem Grande. Seabird 10:3-11 
Hatchwell BJ (1991) An experimental study of the effects of timing of breeding on the reproductive success of Common Guillemots (Uria aalge). J Anim Ecol 60:721-736

Jones MJ (1986a) Breeding synchrony of Cory's Shearwater Calonectris diomedea on Selvagem Grande. Ibis 128:423-426

Jones MJ (1986b) The relationship of egg-size and nest site occupancy with nest type and nesting density in Cory's Shearwater Calonectris diomedea on Selvagem Grande. Bol Mus Munic Funchal 38:110-119
Jouanin C, Roux F, Mougin J-L (1989) Cycles d'affluence des Puffins cendrés (Calonectris diomedea borealis) à Selvagem Grande. L'Oiseau et RFO 59:153-168

Mougin J-L, Jouanin C, Mougin M-C, Roux F (2001) The influence of neighbours on breeding synchrony in Cory's Sheawater Calonectris diomedea. Mar Ornithol 29:51-56

Thibault J-C, Bretagnolle V, Rabouam C (1997) Calonectris diomedea Cory's shearwater. BWP Update 1:75-98 